\title{
Social Impacts of High Dyke Construction and Farmers' Responses: Case of Agricultural Intensification in the Vietnamese Mekong Delta
}

\author{
Thanh Duy Vo \\ The Research Center for Rural Development, An Giang University-Vietnam National University Ho Chi Minh City, An Giang, Vietnam \\ Email address: \\ vdthanh@agu.edu.vn

\section{To cite this article:} \\ Thanh Duy Vo. Social Impacts of High Dyke Construction and Farmers' Responses: Case of Agricultural Intensification in the Vietnamese \\ Mekong Delta. International Journal of Sustainable Development Research. Vol. 7, No. 2, 2021, pp. 28-40. \\ doi: 10.11648/j.ijsdr.20210702.11
}

Received: March 23, 2021; Accepted: April 23, 2021; Published: May 8, 2021

\begin{abstract}
Since Vietnam government adopted a comprehensive reform known as Doi Moi policy in 1986, agricultural sector, especially intensive rice production, has played a critical role in a substantial growth and contributed significantly to poverty reduction in the Mekong Delta. In promoting rice intensification and agricultural diversification, a series of high dyke systems and embankments have recently been installed in many inundation areas of the Mekong Delta to provide flood protection so that farmers could grow rice even during flooding seasons. Local government assumed that farmers in new floodprotected areas are able to diversify and intensify agriculture, particularly rice production, thereby improve local livelihoods. Innovations in artificial hydraulic management and changes in agricultural production, however, have not only generated a great impact on environment and ecology of the Mekong Delta, but also triggered a process of social differentiation, causing the appearance of marginalized groups who must struggle for access resources to maintain their survival. Studies on the aspects of social differentiation and local efforts to cope with such adverse impacts have been rare. This paper aims to investigate recent trends of human intervention to regulate floodwater flows for agricultural intensification in the Mekong Delta and to explore the diversity and dynamics of farmers in adapting with these changes by examining their livelihood strategies. The mixed method comprising participatory rural appraisal (PRA), field observations, in-depth interviews with key informants and household surveys was employed to collect necessary data. The analysis suggests that the local people's livelihoods constitute dynamic, complex and diverse paths to respond to changing social, economic and environmental conditions after the appearance of the high dyke systems. Households and individual farmers differ in the degree of emphasis and choice of livelihood strategies, according to their own capacity in the broader socio-political and economic context and the structure of their internal size, composition and capital. However, the small-scale farmers and poor landless group have been seen at the losing end in the trade-off and thereby excluded from the development process.
\end{abstract}

Keywords: Dykes, Agricultural Intensification, Social Stratification, Livelihood Changes, Vietnamese Mekong Delta

\section{Introduction}

Agriculture has played a significant role in substantial growth and poverty reduction in Vietnam since the central government adopted an economic policy reform known as Doi Moi policy in 1986, a transition from a centrally planned to a market economy. The decentralization of agricultural land, the liberation in agricultural production, as well as other reforms, directly benefited the majority of people, whose livelihoods are closely connected to small-scale agricultural production in rural areas [1]. In fact, the growth of agricultural production has mainly been the result of an acceleration in the intensification of rice production system, in terms of not only an increase in yields but also the expansion of the cultivating area. This transformation of rice production practices began in the late 1960s after the Vietnam government had introduced a number of potentially high yielding 'Green Revolution' rice varieties, together with 
the implementation of land reforms [2]. The considerable improvements in water management, especially the irrigation systems, recently have allowed rice farmers undertaking multiple cropping per year. The intensified process of rice production has consisted mainly of an extension of the irrigated high yielding rice ecosystem, while the other types of less productive rice ecosystems have significantly reduced [3].

However, the monoculture of rice production has stemmed from a variety of conflicts rising in the rice economy. High external inputs, such as chemical fertilizers, pesticides and other forms of agro-chemicals, have led to environmental deterioration and economic inefficiencies [4]. In addition, the price of rice has often fluctuated, and the rice yield itself has decreased over time due to deteriorating soil conditions. Hence, the lives of rice farmers have not greatly improved, because of the comparatively modest incomes earned from intensive rice production. To solve these problems, doublerice and triple-rice cropping systems have been developed in the Vietnamese Mekong Delta (MD). The recent land reform that allows rice farmers in the MD to possess up to 60 hectares per household has enabled a significant increase in rice intensification. Nevertheless, apart from the economic values gained the development of rice intensification has significant implications to the integrity of ecological systems in the MD, especially the wild fish catch, water resource and livelihoods of millions of inhabitants dependent on aquaculture and small-scale agricultural production. The landless poor and small-scale farmer's lives have not improved to a sufficient extent [5].

In recent decades there has been a dramatic rise in the impacts of agricultural intensification and commoditization upon social differentiation in many peasant communities. Husken and White [6] examine the patterns of socialeconomic differentiation brought about as a consequence of the Green Revolution in Java of Indonesia. The study points to the unequal distribution of the benefits of the new technologies and identifies various mechanisms by which this occurs. The transformation of the rural structure as well as the emergence of commercialized peasant agriculture, mark the beginning of social differentiation. In this sense, the larger farmers are able to adopt new technologies more quickly, having greater access to subsidized credit and other inputs. The village-level power structures are usually dominated by these larger landholders who often have access to state patronage, both inside and outside agricultural production. The combination of agricultural production surplus and power also allows them to control the nonagricultural production sector. The accumulation strategies of the landed elites in this context then, involve not only the further concentration of landed property, but also a combination of agricultural intensification and a diversification into non-agricultural enterprises. Therefore, as the authors conclude, the commercial and technological innovations in Javanese rice production have provoked new forms of social differentiation, which have resulted in schisms in the relations between farmers, landless laborers and very small owner-cultivators [6].

Another study by Phrek [7] examines the process of social differentiation in Northern Thailand when Thai government introduced the commercial farming systems in late 1990s. The promotion of "high-value" cash-crops such as vegetables and mix-fruit tree systems, was seen as transforming land use from being subsistence-based to more commercialized. However, the "New Theory" farming system, as a solution to achieve food security, income stability and environmental integrity, significantly affected land use practices in the highlands. The concerns over the highland environment were the disturbance of soil and forest lands by pollutants and the heavy use of chemicals. In addition, the local farmers yield very little profit from the cash crops grown, due to an increase in production costs and a decline in productivity, stemming from the decreasing soil fertility caused by soil erosion. Furthermore, farmers had to borrow money from both government banks and local traders, and subsequently, serious indebtedness was found among Thai farmers in the study areas, where many farmers had to seek off-farm employment in nearby cities, mainly moving to Bangkok to work as wage laborers [7].

In the MD, the increasing social differentiation is often associated with land issues, especially land accumulation, agricultural intensification and commercialization. Intervention through institutional reform (land reform), represents a process by which rural people's differential access to production factors can be regulated. Akram-Lodhi [8] claims that, in the MD, where the main agricultural production of the region is based on rice and its subsequent export, land concentration is quite common. He suggests that land reforms have not supported the poor, yet created "peasant class differentiation". He claims that "the evidence demonstrates the rapid growth of class of rural landless who are largely separated from the mean of production, who survive by intermittently selling their labor, and who are the poorest segment of rural society". Most critics of landmarkets are concerned that the poorest people will be forced into becoming landless and hence dependent upon wage labor; leaving them worse off than before. Therefore, the land concentration process is closely related to the increasing disparity between the rich and the poor [8].

Recently, the Mekong Delta of Vietnam has witnessed significant changes in its agricultural structure, environment and social relations since the central government has developed policies to continue to promote agricultural intensification to increase rice production. It could be argued that while some benefits from intensive agricultural production might contribute to the national economy, household security is seriously threatened, and there are the following signs of social upheaval which could become a possibility if current trends are not corrected and a social safety net is not established. The water intervention projects as such the high dyke construction in this study has promoted rice intensification and cash crop but generated adverse impacts on those marginalized people who do not have enough resource capitals to pursuit the rice intensification 
and agricultural diversification. The concept of "social differentiation" in this study therefore represents not only the social gap between the rich and the poor, the landless and the landed farmers in terms of cash income, but also differences in terms of access to natural capital (such as wild fish and alluvial soil from floodwater), social capital (such as innovation technologies, farmer's networks, and agricultural extension services), financial capital (such as formal and inform credits) and other kinds of resources needed to generate a livelihood. In this sense, the poor, especially the landless poor households, are excluded from the agricultural development process.

Recent studies have demonstrated increasing interest in the issues of high dyke constructions for agricultural development in the MD. Most studies in this scholarship tend to emphasize on aspects of environmental degradation $[9,10]$ and ecological impacts [11] in water-protected areas; the decline of rice yields and impact on farmers' income [12, 13], and economic costs and benefits of the dyke program [14]. Yet, the social impacts associated with the high dyke constructions and the forced transformation of livelihood practices undertaken by local inhabitants have been poorly understood. So far, there has been little discussion about the aspects of social differentiation and the local efforts to cope with such impacts. To identify emerging problems in the everyday lives of the local people, this paper seeks to understand the relationships between national agricultural development project, social differentiation, and local adaptive strategies through a case of high dyke construction for intensive agricultural production in the MD. The benefits from this development project are spread unevenly, which causes greater social differentiation within the MD. More resources have been concentrated in fewer hands. Some people who have bigger landholdings or better financial capital can use their capitals intensively in agricultural production and agricultural services; hence, they can gain better benefits that poor farmers and landless poor do not. While the dyke system has brought benefits in terms of increased agricultural productivity, the water control system has brought new threats to local people. The livelihoods of local people have been significantly affected since some of traditional practices (e.g. fishing) have come to an end. The MD has witnessed the increasing number of landless poor and small farmers to abandon agriculture, to migrate to urban areas for seeking new livelihoods.

This paper highlights that the local people's livelihoods constitute dynamic, complex and diverse paths to respond to changing social, economic and environmental conditions after the appearance of the high dyke systems. Households and individual farmers differ in the degree of emphasis and choice of livelihood strategies, according to their own capacity in the broader socio-political and economic context and the structure of their internal size, composition and capital. However, due to lacking capital assets, the small farmers and poor landless households have not benefited from the dyke construction; therefore, these people have been excluded from the development process.

\section{Research Methods}

\subsection{Case Study Area}

In this study, Cho Moi district of An Giang province has been selected for the research site in the Vietnamese Mekong Delta (Figure 1). This selected area located in the high flooding zone has a general geographic, land use pattern and socio-economic structure characteristics of most other rural communities in the inundated area of the upper part of the MD. Cho Moi district has been described as the first location that local government had installed a series of high dyke system to regulate floodwater for intensive agricultural production in the MD. Since the appearance of the high dyke system, rice production has been intensified up to three crops a year while other traditional agricultural productions have been diversified toward commercial cash-crops. Furthermore, the district's economic structure has also been gradually transformed, moving from an on-farm to a non-farm-based economy. As the dyke system was implemented nearly fifteen years, its adverse impacts on the ecosystem, farming practices and local livelihoods have become apparent.

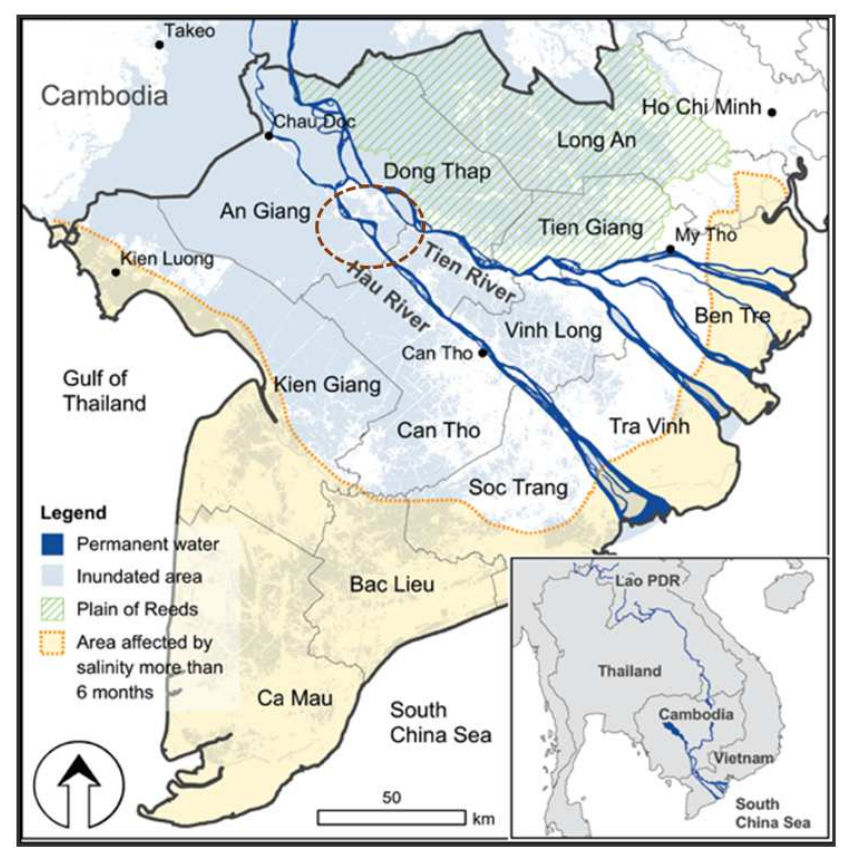

Figure 1. Flooding zone of the Vietnamese Mekong Delta and the selected study area.

\subsection{Methods for Data Collection and Analysis}

\section{Data Collection}

Mixed-methods approach [15] was applied in this study. Qualitative information gathered from participatory rural appraisal (PRA), in-depth interviews, and field observations, while quantitative data collected from household interviews to examine the recent trends of human intervention to regulate flood-water flows for agricultural intensification in the MD and to explore the diversity and dynamics of local inhabitants in adapting with these changes by exploring their livelihood strategies. 
The qualitative data was gathered during the participatory rural appraisal - PRA (eight focus group discussions) conducted with four social groups (landless poor, landed poor, medium, and better-off farmers) and fourteen in-depth interviews with local officials, agricultural and environmental scientists, farmers and fishermen. Semi-structured questions were applied to investigate the recent changes in the ecological systems, farming practices, inhabitants' livelihoods, and their adaptive livelihood strategies to deal with changes. The quantitative data was collected through the structured questionnaires, targeted on four household groups, which informs the quantitative analysis. The field data was collected from August 2014 to November 2014. The details of methods were applied in this study:

1. Participatory Rural Appraisal-PRA: There were two PRAs being applied in each social group. The first was a general discussion open to address questions concerning dyke construction, environmental degradation, land and water management, and wealth ranking of Cho Moi district. The second discussion illustrated on specific issues such as income sources and changes in income-earning activities before and after the high dyke construction, livelihood choices, perceptions on soil degradation and agricultural production return.

2. Wealth ranking: Participants in the PRA discussions structured the households of one section of their community into four wealth groups, namely the betteroff, medium, landed poor, and landless poor household groups using local people's perception of wealth which included variables such as cultivated land, livestock, cash income, employment type, number of children and laborers, types of house, among other several unidentified criteria.

3. In-depth interviews: Key informants in four household groups were carried out to understand farmers' choices of production systems and their management strategies. Besides farming households, informants in landless household group were also selected for in-depth interview to analyze more recent changes in their livelihoods and their economic performances.

4. Household interviews: Ninety households were classified into four social groups for household survey. Household heads and spouses were the main focus of open-ended questionnaires which were designed to measure most of the variables elicited during the PRA discussions.

Data Analysis

Covering all data collected from various sources such as household surveys, key informant's in-depth interviews, focus group discussions and participatory observations, the quality and quantity of secondary data also helped me identifying the research questions as well as issues that emerged throughout the fieldwork. The information was then used to analyze changes in the farming systems and practices, local livelihoods, social relations, and the impacts of the government agricultural policies on local livelihoods.
Moreover, the collected data further helped to understand the process of social differentiation brought about as a consequence of agricultural intensification through the lens of the government agricultural development at the local level.

\section{Results and Discussion}

\subsection{Flood Dynamics in the Mekong Delta and Hydraulic Interventions to Maintain Vietnam's "Rice Basket”}

The Mekong Delta of Vietnam is amongst the largest deltas in Southeast Asia which plays an important role in Vietnam's socio-economic development [16]. The MD produces approximately $50 \%$ of staple food and $60 \%$ of fish production of the entire nation [17]. As a result, the MD is often regarded as the "rice basket" of Vietnam since its crops feed and sustain the inhabitants and make Vietnam the second largest rice exporting country in the world. However, given nearly four million hectares of agricultural land and the total population of nearly 18 million living primarily on agriculture production, this region has been faced with growing pressure to ensure the national and global food security [18].

The delta's hydrological condition is denoted by local rainfall, the Mekong river's discharge and the tidal fluctuations, all of which affect the local water regime [19]. Annual flooding season starts in July, lasts until November and even December in low-lying areas. About two-thirds of the MD (from 1.2 to 1.9 million hectares) is affected by overbank flooding during the peak of flooding season [20]. Flood-prone areas in the MD are home to about 8.5 million people, of which nearly 2.5 million people live in deep floodwater zones (up to three meters), three million people live in medium flood zones (up to 1.5 meters), and the rest live in low flood zones (below one meter) [21].

For many generations, local inhabitants in this region have been exposed to a nature which was shaped by floodwater flows and they have resided and adapted to the environment surrounding without much human interference into the natural hydraulic system of the delta [22]. Flooding season has always had two-sided effects on local people's lives. On one hand, the MD has been exposed to permanent threat of natural disasters in the form of floods in the rainy season. On the other side, the Mekong river bring many benefits such as natural soil fertility and agricultural productivity to the region.

The natural pattern of flood and retreat is significant to the MD's ecology [23]. Flood waters help to clear pests, not least rats, as well as to deposit valuable nutrients that are crucial to the high yield characteristics of the local agricultural production, particularly that of rice [2]. Flooding season is also a time of abundant fish and of renewal for the rice fields. Hence, a discourse of "living with floods" is part of such cultures [24].

Over the last few decades, to establish the ground for national development, Vietnam government has endorsed many crucial strategies for socio-economic development in 
the MD. The intensification, diversification and commercialization of agriculture continued to be considered a key solution to deal with the pressure of high population growth and the limitation of non-farm opportunities in the MD. Particularly, intensive rice production is the avowed goal of Vietnam government to enhance national economy, to alleviate poverty, and to ensure national food security. To achieve this, hydraulic interventions have been initiated in flood plains to support the intensive agricultural production in the MD that directly effects on local people's livelihoods [9]. Since late 1980s, Vietnam government had invested in a number of canals to drain floodwater from low-lying areas to strengthen the drainage capacity for agriculture. Particularly, during the 1990s dozens of large canals had been excavated in the flooded areas of An Giang and Kien Giang provinces, two largest areas of rice production in the MD. These canals were found to be effective during the historic floods in 2000, 2001 and 2002 [18].

Water regime management continues to perform a major role in promoting agricultural diversification and rice intensification in the MD [25] so as the delta have experienced a dramatic increase in hydraulic management for its agriculture since early 2000s [22]. To reduce the inundation areas in order to extend rice cultivating area during flooding seasons, new flood control measures as such high dyke systems has been constructed in the MD [2]. These measures are "closing off" the MD to floods, to make farming systems less dependent on natural conditions and to expand multiple cropping to former flood-prone areas. The present water-control projects are in line with those national policies from the late 1980s and early 1990s; emphasizing the intensification of rice production in order to enhance the food security of the nation [26]. This development initiative has included a strong belief in human mastery over nature and the waters of the MD which have underestimated the complexity and integrated nature of the ecology and livelihoods of thousands of inhabitants in the MD. These development efforts, while successful in some dimensions, have also created new risks, especially for those members in the poor and marginalized groups.

Table 1. Total rice productivity of Vietnam and the Mekong Delta (Units: 1,000 tons).

\begin{tabular}{llll}
\hline \multirow{2}{*}{ Years } & \multirow{2}{*}{$\begin{array}{l}\text { Total productivity of } \\
\text { Vietnam }\end{array}$} & \multicolumn{2}{c}{ The Mekong Delta } \\
\cline { 3 - 4 } & $34,538.9$ & $16,754.7$ & 48,50 \\
\hline 2000 & $36,960.7$ & $17,821.6$ & 48.21 \\
2002 & $39,322.9$ & $18,691.0$ & 47.53 \\
2004 & $39,621.6$ & $19,488.2$ & 49.18 \\
2006 & $38,729.8$ & $20,669.5$ & 53.37 \\
2008 & $40,005.6$ & $21,596.6$ & 53.98 \\
2010 & $43,737.8$ & $24,320.8$ & 55.61 \\
2012 & $44,974.6$ & $25.245,6$ & 56.13 \\
2014 & & & \\
\hline
\end{tabular}

Sources: GSO, 2014.

The turning point came in the year 2000 when high dyke systems were constructed in many sub-regions of the MD. To start this intervention project, the local government built a high dyke system in Cho Moi district of An Giang province. By the year 2003, the whole Cho Moi district within 21,858 hectares was completely protected from annual flood. High dyke construction was then multiplied to many places throughout the MD [2]. Economic growth has been improved as agricultural productivity has significantly increased. Total rice productivity in Vietnam (Table 1) raised dramatically from 34.5 million tons in 2000 to nearly 45.0 million tons in 2014 [27]. Majority of this increasing rice productivity was produced in the additional rice crops inside the high dyke systems of the MD. Such a rapid expansion of rice productivity made it possible for Vietnam to become the second rice exporter after 2000, exporting nearly 7.5 million tons of milled rice in 2014, of which over 90 percent of rice export was produced in the MD [27].

\subsection{Impacts of High Dyke Constructions on Rice Production and Wild Fish Catch}

Water-control measures for agricultural intensification, particularly intensive rice production, have challenged the environmental sustainability and social equity in the MD [26]. Soil fertility is a critical factor in support of agricultural production the MD as in the low-lying areas, inundated by floodwater for four months a year, each cubic meter of floodwater contains up to half a kilogram of sediment, silt and organic matter. This soil, a natural fertilizer, has helped to form the delta and has made its soil very fertile [11]. Sediment also contributes significantly to minimizing crop diseases and increase rice productivity [28]. Nevertheless, this free sediment no longer exists in the fields due to the introduction of the high dyke system. The possibility of decline in soil productivity stems from the decrease of rice yields [13]. Studies have shown that after a few years of the high dyke constructions, total productivity from the triplerice crops inside the flood-protected areas is less than total productivity from the previous double crop system outside the high dyke system due to reduced soil fertility [12].

In addition, the spread of intensified rice production and cash-crops, and the decline of fertility in cultivated land, caused by the high dyke systems, has led to a greater application of agricultural inputs. A recent study suggests that most farmers in dyke-constructed areas agreed that the application of chemical fertilizers increased to make up for lost nutrients in soil. More chemical fertilizers were used inside the high dyke systems than those in the flooding areas, especially Urea. Particularly, the use of Urea, Kali, DAP, and NPK 20-20-15 between two areas reflected a clear disparity of 53 kilos, 21 kilos, 7.4 kilos, and nearly 40 kilos per ha respectively [28]. Increasing investment costs stem from the decline of farmers' income. The increasing amount of agrochemical used also damage the environment, especially reducing soil and water quality. The social group that mostly affected by the profound changes after the high dyke construction is small-scale and poor farmers, who have lost 'free sediment' from the floodwater and therefore have to invest much more in agrochemical inputs [2].

Moreover, local inhabitants are no longer able to gain their 
livelihood from fishing because a high embankment embracing the boundary line was set up as to block fish moving from Mekong River into the rice fields during the flooding seasons. [12] Figures out that there was a significant reduction in the fishery capture output of $1,072 \mathrm{~kg}$ per household per year inside the dyke areas compared natural overbank flood areas in An Giang province. Before the dyke project, each household caught $1,470 \mathrm{~kg}$ fish per year, but this amount was only $398 \mathrm{~kg}$ per year after the construction of dykes. Given such complexities, the rural poor households are directly affected since they lack sources of capital needed for intensive agricultural investment. It was found that the majority of this household group was landless and of unstable employment. They mainly earned their living from fishing [28]. This also affects small-scale farmers whose livelihoods also relied on fishing or other opportunities created by flood-based farming during flooding seasons. This opportunity has now disappeared with the appearance of the high dyke system. The decline in livelihood opportunities has pushed these people to become even more marginalized. They must change their livelihood, usually by moving out of the district to seek other opportunities in urban areas.

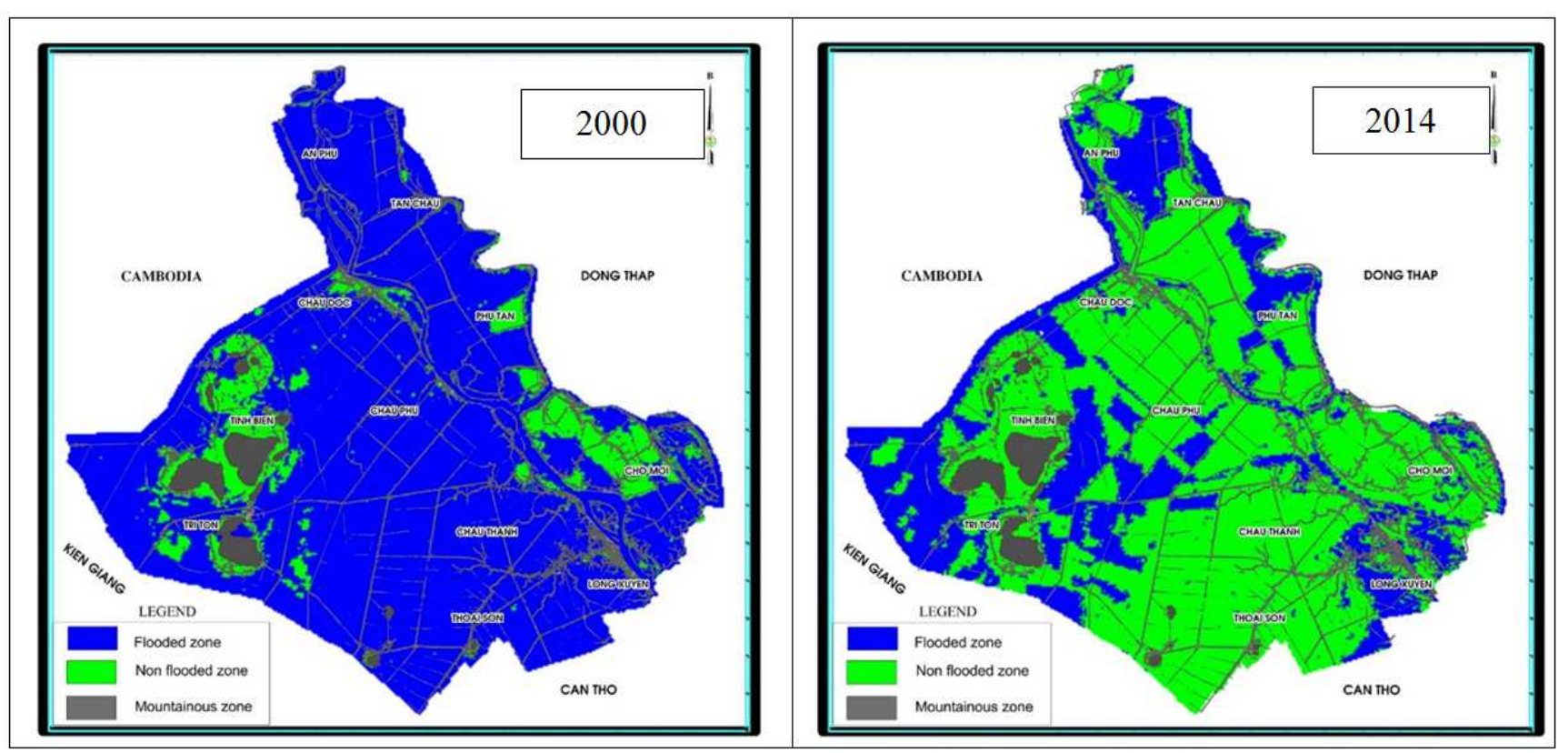

Figure 2. The reduction of flooded zone in An Giang province due to the high dyke constructions. Map by Pham Duy Tien.

A significant social cost associated with the high dyke system is the change in farmers' working patterns. A study reveals that farmers experience greater levels of stress and exhaustion because their traditional 'resting time' during flooding seasons has been taken away when they must engage in the intensive agricultural production year around [26]. The workload has remarkably increased as farmers must work harder to maintain household income due to the degradation of soil fertility. The new agricultural productions including baby corn, hybrid maize, young cucumber, beans, and other commercial cash-crops have been dominant in the delta's cropping pattern. The people have been busy all year around because they now cultivate three rice crops, and other 4-6 cash-crops a year. The current farming systems are strongly dependent on the availability of water, finance, labor, soil quality, and market prices. Study by Thanh [2] suggests that the high dyke systems might create greater risks as local infrastructure and livelihoods have adjusted to the flood-controlled environment. If the floodwater levels exceed the safety margin of the control structures, the damages are likely to be greater than before because the farming systems and infrastructure that the high dyke systems have enabled, which are no longer adjustable to the flood levels, would be severely destroyed.

\subsection{High Dyke Constructions-Induced Social Impacts}

\subsubsection{Wealth Ranking of Social Groups in High Dyke Areas}

The wealth ranking conducted during focus group discussions shows that there are four social groups inside the high dyke system (Figure 3). The number of poor households are lower than that of the better-off social group, and the medium households comprises the largest group in the community. The qualitative analysis explores that cash income earned is one of the most important indicators of wealth and poverty situation of households in the high dyke systems.

\section{The Better-off Farmers' Group}

Members in the group of well-to-do farmers were those who usually possessed large area of farmland (over 1.5 hectares per household) and typically dominated agricultural input services, including agricultural machines, irrigation pump stations, rice seed breeding, rice mill, etc. in the community. Better-off farmers often operate farmland and started the crops earlier than other farmers as they had tractors and owned pump services. 


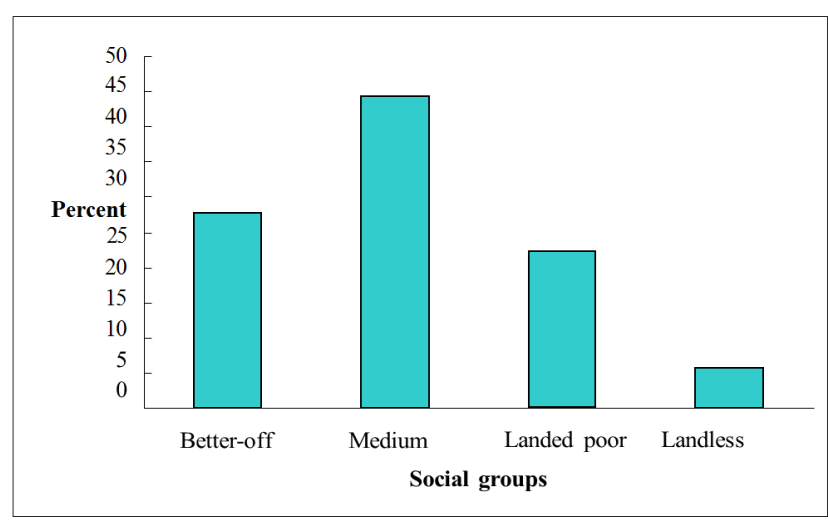

Source: Focus group discussions, 2014.

Figure 3. Social groups in Cho Moi district (sample selections).

Better-off farmers tend to transform their farming systems from mono-rice production to cash-crops which typically required higher investment for input applications that smallscale farmers hardly afforded. These new crops included baby corn, ginger, taro, onion, and tomato to provide raw materials in the form of farming contracts for a local food processing factory. They had available resource capitals to apply successfully in their farming activities. This means better-off farmers were usually able to operate their farms with higher added value crops as they could sell products in a higher price for the factory. Several members of these betteroff farmers were also working in the community as local officers so they could perform as patrons of other social groups in the district. These rich farmers were able to send their children to pursuit higher education in urban areas so that their families could accumulate more wealth in future.

The Medium Farmers' Group

The medium household group occupies over $45 \%$ of the total population of the district who have been undertaking multi-active in their livelihood strategies. These households have fewer resources, so the engagement on intensive agricultural production is less active than that of the betteroff farmers. Due to the limitation in landholding, averagely 0.5-0.9 hectare per household, medium farmers usually succeed in using their family labors more intensively in growing cash-crops that particularly required more labors to carry out farming activities. A small proportion of household farmland had been used for rice cultivation for home consumption, while the rest was dedicated for cash-crops to generate main household income. Due to the fluctuation of the market prices, and low returns from the farming activities, these people were observed easily to fall into the poor group whenever they encountered risks such as crop failure, natural hazards, or family member's sickness.

\section{The Landed Poor Group}

The landholding of this social group is typically less than 0.5 hectare per household. These small-scale farmers preferred to use a small parcel of land to cultivate rice for home consumption and devote the rest to grow cash-crops for generation cash income for daily expense. Almost every investment decision of the poor householders was likely a gamble because whenever they faced crop failures or family problems, they usually sell livestock, even the land to pay the debts. Agricultural wage labor and out migration were commonly seen as a way of reducing pressure on their inadequate landholdings and household's surplus labor.

The Landless Poor Group

The landless poor is the smallest social group in the community, comprised only about $5 \%$ of total households, yet these people are poorest and marginalized inhabitants in the district. The group is composed of young people who have just separated from their parents' household after getting married, without any inherited land. Some households have many children but no land for many generations. Some old couples have no children or loss their children in disease or migration. Most of these households lived on fishing and agricultural wage labor before the dyke construction. In these households, the young tend to migrate to work as wage labor in urban factories while the elderly remain in the district to take care of their grandchildren.

\subsubsection{High Dyke Systems Driven Social Differentiation Process}

Livelihoods in Cho Moi district consisted of on-farming and non-farming activities. Although non-farm became increasingly important in household economy, the subsistence family farms were still kept at different scale by multiple ways. Most of farming households constructed their livelihood strategies based on subtle combinations of farming, including cattle raising, cash-crops and rice growing, non-farm activities and migration to deal with increasingly daily expense. It can be said that the differentiation among households in terms of livelihood resources (five types of capital assets - an analysis of Frank Ellis [29]) have allowed the modes of livelihood articulation to exist at local level. To examine the sources of cash-income and expenditure through on-farm and non-farm activities, as well as to study how they manage the surplus for further income generation or deal with the deficit, helps to understand the existing livelihood strategies of inhabitants inside the high dyke systems.

Household Income Generation

Revenue generation of households comes from different livelihood activities depending on the resource capitals of different social groups. The primary sources of income of the landed household group are from agricultural activities, including production of intensive rice and cash-crops, and livestock, which is combined with all the other activities. The raising prices of livestock and cash-crops are resulted in the increasing importance of these livelihood activities for a number of households in Cho Moi district. Other income sources such as agri-businesses, agricultural collectors, salaries from government employment, grocery, and carpentry are considerable important, especially to better-off households. Almost all household groups are jointed in these important revenue-earning activities, with an exception of the landless household group.

The income-generation profiles of four social groups are 
shown in Figure 4. The income sources earned by better-off households are mainly from cultivation, livestock rearing and agricultural input services, accounting for 31 percent, 36 percent, and 17 percent of household income, respectively.

The cultivation of medium households is slightly more essential than that of the better-off households, accounting for 36 percent of total household income; livestock accounts for 33 percent, and agricultural wage labor contributes for about 8 percent, meanwhile other livelihood activities play a considerable role in household economy, contributing up to 25 percent. The research finding shows that incomegenerating sources of the medium group are unstable. Hence, households in this social group usually invest in all possible livelihood areas to ensure the cash-income for household survival.

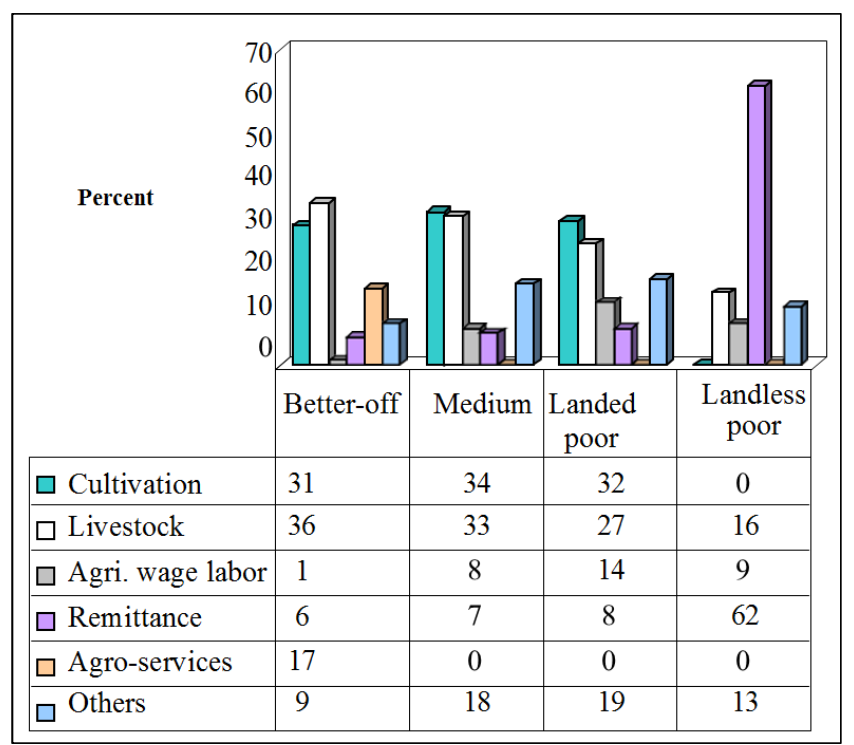

Figure 4. The profiles of household income for four social groups in Cho Moi district. Source: Household interview, 2014.

Despite possessing small area of farmland, cultivating activities and other agricultural-based livelihoods in landed poor farmers are considered the most important activity, in which cultivation brings in 32 percent of total household income, livestock accounts for 27 percent, and agricultural wage labor contributes to 14 percent of household income. The remaining 25 percent of household income are from migratory remittance and other activities. In contrast to better-off households, whose remittance from their children working in private enterprises or state-owned companies in cities, accounts for 8 percent of total income. Revenue from remittance amongst landless poor households is the most important source of household income, accounting for 62 percent. Livestock contributes to only 16 percent, while agricultural wage labor and other activities make up 22 percent of family income.

For landless poor households, the remittance is usually used for buying calves, paying children's school fees and daily expense. Livestock rearing in poor landless households is the responsibility of the elders who remain in the district while young couples travel to city to work. For the poor farmers and landless poor, agricultural wage laborers were paid on daily basic. Due to the nature of small landholding and limited resource capitals applied for intensive agricultural production, the landless poor and small-scale farmers earn very little from agricultural intensification after the appearance of the high dyke construction. This also explains why remittance from migration are very important to the poor and landless households.

Cash crops and livestock rearing are new livelihood components after the high dyke has been constructed which generate most income for local farmers while remittance is the most important income source of the landless poor. The role of rice production in household income decreases as most farmers tend to reduce area of rice production and increase area of cash-crops and fruit garden. Most better-off and medium households grow rice for both market and home consumption while poor farmers usually maintain a small plot of rice land for their own subsistence.

\section{Household Expenditure}

The expenditure patterns of four social groups are differently according to the economic situations of each social group. The type of expenditure is determined by the wealth which indicates both household consumption and investment. Majority of respondents illustrate that expenditures related to household consumption are popular because these expenditures associate with fundamental needs such as food, nutrition, health and education. Expenditure items of different household groups are presented in Table 1.

Expenditure on food items is significant amongst the landed and landless poor households because farming activities such as rice and vegetables on compound farms, is likely not enough to feed family members. In contrast, the medium and better-off farmers do not perceive spending on food as main expenditure of households as the amount of food purchased is only limited to ingredients and other items that they cannot produce.

Purchasing farm inputs makes up a large proportion of expenditure of farmer's households. This study found that there has been a remarkably decline in soil fertility and the decrease of rice yield inside the high dyke systems. Due to the declining soil fertility, local farmers must apply an extra average of $35.9 \mathrm{~kg}$ of nitrogen fertilizer per year inside the high dyke areas. The household survey also reveals that the annual rice yield has decreased 1.4 tones/ha after 2 years and 1.48 tones/ha after 6 years of the high dyke construction. With the average price of VND 5,000 per $\mathrm{kg}$ of rice, the profit of rice farmers decreased VND 7.0 million and 7.4 million/ha per year, respectively. Owning to the lack of financial capital, small-scale farmers, especially poor farmers, often do not access to adequate amount of inputs, especially chemical fertilizers, at the right time for obtaining high yields. In addition, they are generally unable to buy sufficient quantities of fertilizers and to cover other expenses for field operations due to lack of credit. Besides, since rice cultivation contributes over 95 percent of total farming income among poor farmer's households compared to 54 
percent among the better-off households, the increase in input applications (e.g. fertilizer) and decrease in rice yield after constructing dyke system have stronger negative impacts to the poor than better-off farmers.

Table 2. Ranking household expenditure items in Cho Moi district.

\begin{tabular}{|c|c|c|c|c|}
\hline \multicolumn{5}{|l|}{ Rank } \\
\hline Expenditure type & Better- off & Medium & Landed poor & Landless poor \\
\hline Foods: Rice and ingredients & 3 & 2 & 1 & 1 \\
\hline Farm inputs & 1 & 1 & 2 & 5 \\
\hline Education & 4 & 5 & 3 & 4 \\
\hline Health care & 4 & 4 & 5 & 4 \\
\hline Transportation & 5 & 6 & 4 & 3 \\
\hline Debt repayment & 5 & 3 & 3 & 2 \\
\hline Dyke construction, irrigation fees and other contributions & 7 & 5 & 4 & 7 \\
\hline Social activities: weddings, naming ceremonies, funerals, festivals... & 2 & 5 & 6 & 5 \\
\hline Others (clothing, fuel, etc.) & 7 & 6 & 6 & 7 \\
\hline
\end{tabular}

Source: Focus group discussions, 2014. (Number 1 is the top priority)

Spending on social services such as healthcare is remarkable to the landed poor and landless families because it might lead to a significant decrease in family's assets in case of people have serious sickness that needs long-term treatment in hospital. In terms of investment for education, it is more popular for poor landless poor to withdraw their children from school as they cannot bear the cost when the children reach beyond the secondary school.

The other costs such as household appliances, transportation, clothing, etc. were ranked the least, probably because of the nature of rural location of the Mekong Delta. Irrigation and dyke construction fees are concerned by all social groups. However, it is likely less impacted on the 'non-poor' farmers as they are usually dominating pump services in the district, thereby evading production cost. Most farmers have to pay for dyke construction fee according to their cultivated landholding; however, the poor farmers seem to contribute much more for these kinds of fee compared to their modest agricultural return.

In sum, expenditure of four social groups is increasing, yet the productive nature for the 'non-poor' households makes it useful and profitable while its consumptive nature for the poor makes them even more marginalized.

\subsection{Livelihood Strategies of Local Inhabitants After the Appearance of High Dyke Systems}

Given the profiles of income generation and expenditure have been presented, a critical question emerged is how local inhabitants could survive or create desired livelihoods to adapt to profound changes. Each household group applies variety of livelihood strategies according to their own resource capitals. Local inhabitants sustain their livelihoods by using income-earning strategies, expenditure-reducing strategies, and migration strategies. Poor households usually use short-term strategy to overcome the hardship while other social groups tend to adopt long-term livelihood strategies to mitigate the adverse impacts, or to improve their household economy.

\subsubsection{Income-Generating Strategies}

The revenue sources of four social groups are dynamic and changing according to new income-generating opportunities emerged after the high dyke construction. Intensifying agricultural practices, especially cash-crops and fatten livestock, and increasing non-farm activities are two popular trends that can be described as land management strategy and multi-activity strategy, respectively.

Tendency One: Land-use Management Strategy and Crop Diversification to Reduce Risk

Having better access to resource capitals, better-off farmers are often seen as first cultivators whose land-use patterns have been quickly changing from rain-fed rice and other traditional crops, which require good soils but sold in lower prices, to intensive rice production and cash-crops, which get higher yield, yet typically require more agrochemical apply. The land-use strategy of those better-off households could be perceived as market driven as they mainly focus on particular cash-crops that the local agricultural processing companies demand. The farming contracts with these processing companies help better-off farmers to sell products in higher prices, so they could accumulate more wealth.

In contrast, households in medium social group, who own smaller size of farmland, are very selective in taking possible strategies that can maintain adequate livelihoods. These farmers tend to change from traditional crop patterns to some other kind of cash-crops if they see market prices being high enough to compensate the production cost from agrochemicals used in the field.

With the introduction of new varieties of baby corn and hybrid maize, local farmers began to expand their farms which led to the significant decrease of paddy rice area in the district. Discounting subsistence production in which all households engaged, the major household economy and sources of income for local people were rice and corn. Moreover, many households were engaged in fatten cow rearing since farmers can utilize by-products from baby corn as feed for livestock. An important development that came with the introduction of baby corn and livestock rearing were the increasing significance of credits and loans which led many Cho Moi district into the vicious cycles of debt and repayment. The better- off farmers have enough financial 
capital to cope with the debts in case that the crop or livestock rearing failure.

Sine 2003, the District's People Committee was actively promoting the intensive production of new crops such as baby corn, hybrid maize and cash-crop varieties. By signing farming contracts with local agricultural processing companies, farmers were eligible for obtaining credits and loans from the Bank of Agriculture and Rural Development. Mr. Nam and many farmers in Cho Moi district decided to join the project; they took out loans from the bank and started cultivating baby corn and rearing fatten livestock. Through these programs, agricultural officers planned to gradually convert land-use from mono-rice cultivation to cash-crop promotion programs for higher returns, however, demanded higher toxic chemical applications. In fact, the high dyke construction accompanied with land use conversion has resulted in the soil erosion and the depletion of soil nutrition resulting in the decline of soil fertility. The cultivation of hybrid species also aggravated the spread of diseases and insects. The cultivation of high yielding varieties inevitably led to the increasing use of chemical fertilizers and pesticides. Mr. Nam reminded:

The application of chemical pesticides and fertilizers helps to increase yields during the first few years. But soon after, the amount of fertilizers required increase substantially, resulting in rising investment in agricultural production. The increase of the land use rotation and repeated application of chemical fertilizers also had an adverse impact on soil quality, making it harder and more difficult to plough; the crops were limited to absorb the nutrition from the soil. The use of chemical pesticides reduced pest only in the initial period. In the long run, we needed to apply increasing amounts of pesticide to deter pests, either by increasing the volume or increasing the concentration. Our health was also seriously affected by the use of these agrochemicals.

The most recent cash-crops such as hybrid maize, baby corn, baby cucumber, vegetable soybean have been introduced to farmers inside the high dyke systems. However, the capacity to adopt or shift among crops is likely constrained by household savings and resource endowment of different social groups. Those better-off farmers who have invested in a large herd of livestock rearing could easily move between new cash-crops because they tend to use large amount of agricultural by-product, for instance baby corn's stems, for feeding livestock. As a result, they could take advantage of this integrated farming systems and generating more cash income from both cash-crops and livestock production.

The majority of land poor households also prefer to combine baby-corn cultivation and livestock rearing in their farming systems. Despite of owning small area of farmland, the intensification of baby corn production, within five to six crops per year, helps small-scale farmers utilize this agricultural by-product on small-scale livestock production, therefore maintaining household income year around. Moreover, small-scale farmers could also reduce production cost by using cow manure as organic fertilizer on the babycorn cultivation. This strategy could be perceived as a kind of sustainably agricultural intensification amongst small-scale farmers due to the land fragmentation in the Mekong Delta.

Small-scale farmers in the poor household group usually adopted both traditional and new agricultural farming systems. These farmers intend to move away from cash-crop production that demand higher agrochemical inputs. The poor farmers usually choose to grow old crop varieties, socalled 'easy crop' (e.g. corn), to avoid risks, rather than trying new cash-crops which are often required higher level of input application. However, when they see the price of a particular crop in the previous season in that high, they tend to concentrate on such kind of crop in next seasonal crop.

Different from the subsistence theory of production, farmers inside the high dyke system of Cho Moi district express a high level of market integration by producing specific cash-crops accordingly to the market's demand. The production of popular cash-crops such as spring onion, vegetables and tomato are sold in local markets, while newly introduced crops such as young cucumber, baby corn, vegetable soybean, and maize consumed by the urban population, or agricultural processing factories for export. Other crops such as chili, okra, long yard bean, cabbage and vegetables are growth during the wet season that farmers in inundated regions cannot grow. The level of market integration of different social groups is dependent on their wealth status. The richer the farmers, the more integrated it is into the market, as indicated by the amount of livestock and agricultural products sold in the market and their capacity to negotiate better prices. Some better-off farmers who have trucks can even transport their agricultural products directly to the processing factories or markets in inner cities.

With a rapid rise in the production cost, many farmers, especially the medium and small-scale farmers have easily been trapped in debts. The capacity of these farmers to repay the debts had decreased, resulting partly from the steady decline in the prices of agricultural products and the increase in interest rates. Borrowing was needed not only for investment in production, but also to cover living expenses. Fluctuations in agricultural prices also increased the chance of indebtedness, especially when prices fell substantially. Mr. Nam and other farmers had to bear the costs and risks of investment and production; more time was spent in intensifying production.

Tendency Two: Multi-Activity Strategies

The second popular trend of local livelihood strategies is the transformation of household members from on-farm activities to non-farm activities in order to diversify household income sources. The present distress of income generation after the high dyke construction stems from members of different social groups involving in non-farm activities. The medium and poor household groups deploy this strategy as long-term income generation. Local agricultural processing factories have recently employed an increasing number of workers from the medium, small-scale farmers and landless poor households. Processing baby corn, 
vegetable soybean, young cucumber and catfish products has become major employment options for most laborers in these social groups. Members in the better-off household group are usually represented in these factories as labor managers, middlemen or agricultural product collectors for these processing factories.

The study also finds that almost all agricultural services such as agrochemical supply, seed breeding, tractors and combine harvesters, and irrigation pump services are dominated by those better-off farmers. On the other hand, Farmers in the medium social group usually engage in petty trading of goods such as grocery, fruits, coffee and foods in local markets. In contrast, poor households are hardly engaging in petty trading mainly due to lacking initial capital needed; however, they are able to generate income from other activities such as street vending, lottery ticket selling, basket making, just names a few. The level of wealth and asset possession are decisive factors to help people diversify their desired livelihoods as the better-off typically engage in more profitable non-farm activities.

\subsubsection{Reducing Expenditure Strategies}

Another strategy to maintain household livelihoods observed on four social groups is expenditure-reducing strategy which involves a decrease in expenditure spending on agricultural production, food, education, healthcare, and social activities. For those households processing fewer capital resources like small-scale farmers and landless, the investment in new livelihoods is a gamble. Hence, the best option for these social groups are to make use of available scarce resources to make cash-income. Reducing expenditure strategies are often seen in farm management, food consumption and general livelihood activities.

Farm management amongst farmer groups seeks to minimize the cost of agricultural production such as reducing agrochemicals application, restricting fertilization to specific crops and land types, burning rice straw or burying grass for organic fertilizers, utilize household labors as substitution to machinery.

The expenditure-reducing strategy is also common among migrant workers from the poor household group living in central cities with highly spending cost. These workers usually choose to buy cheap foods, to stay in reasonable accommodations, or to share the accommodation with other migrant workers.

The 'forced' reducing expenditure of poor households helps them adjust to trends and shocks. Members of impoverished families react to the distress simply by withdrawing children early from school; some avoid hospital treatment unless the sickness becomes critical while other families are seen to postpone their children's marriages.

The better-off farmers attempt to reduce production cost in any possible crops they have invested. The increasing use of available cow manure from large herds of livestock helps better-off famers to reduce the cost of chemical fertilizers application on cash-crops.

Farmers in the medium and small-scale households usually prepare the farmland by hand, or less relying on tractors, depending on the farm size and household labor availability. Large amount of compost from burning rice straw remains on the field after the harvest forms a source of fertilizer. Moreover, these farmers make the best use of small piece of upland by growing grass for livestock, while the low-lying land is used for cash-crops and rice cultivation. In home gardens, farmers grow fruit trees, raise fish and chicken for home consumption. The diversification of agricultural activities supports these farmers to better utilize their limited resource of farmland and minimize the risks from relying on a single crop.

\subsubsection{Rural-Urban Migration}

Seeking potential opportunities away from home villages in order to improve household income or to secure household livelihoods is remarkable decision among poor households in Cho Moi district after the dyke construction. Migration has become a recent trend in Cho Moi district after the dyke construction due to the decline of local livelihoods whereas non-farm activities have been limited in the location. All social groups have experienced some migration in their families. Remittances from urban cities helps migration families improve financial capital resources which are used for various purposes such as local investment in both on-farm and non-farm activities to generate more income, household appliance purchase, or children's education. This study supports the finding of Yos [30] who suggests that remittances from urban areas help in land investments or building up entitlements by those who stay behind in rural areas.

Better education and good opportunities in income generation are pull factors for the better-off households, while poverty is a push factor for the poor families. Members of better-off households migrate mainly for education purpose. In contrast, those of medium, land poor and landless poor move out due to scarcity of jobs available in their home villages. The migration occurs in the land poor and poor landless groups more frequently than other social groups. In these families, the only ones remain in the village that because they are too old to be employed in factories, or they have no contacts in urban destinations.

An increase in migrations is typically resulted from the accentuated forces of 'pull factor' from the prosperous urban economies and 'push factor' from the stagnant or deteriorating local economies [29]. In fact, increasing debt and uncertainty of income generation have forced many poor people in My An Village to seek out job security and cash income outside their hometown. From 2004 to 2008, there was an unprecedented increase in off-farm wage laborers among local inhabitants. The debts and low returns from agricultural production have led to many inhabitants increasing dependent on migration and wage labor. Mr. Nam was inundated with debt after several years of production of hybrid corn and fatten livestock. In 2005, he migrated to Ho Chi Minh City to work as a wage labor. He reminded:

It was very difficult for us because my children were small. 
But we had no other choice. I had to migrate to city to search for alternative source of income to repay the debt.

In short, the high dyke system causes an increasing cost of agricultural production without a compensate increase in farmers' income as the soil inside the dyke system is exhausted due to the lack of sediment from flood and the highly intensive production of rice and cash-crops. Nevertheless, the response of various social groups to these contingencies and trends is much dependent on their adaptive capacities modified by emerging of existing trends, contingencies and shocks generated by the man-made intervention on water management for agricultural intensification.

\section{Conclusion}

The waters of the Mekong Delta have recently been brought increasingly under human regulation for agricultural intensification and diversification. Rice production has been intensified and triple rice cropping has been expanded inside high dyke system areas that formerly produced only single or double crops. Although the damage from natural waterrelated hazards have been mitigated, the water modification efforts have led to new man-made risks that this paper attempts to highlight.

The role of intensive agricultural development has been paradoxical. It aims to alleviate poverty in the Mekong Delta, yet the result is likely on the contrary, increasing social differentiation because the landless and small-scale farmers have no resources to make the high and risky investments required for starting with agricultural intensification. The problems and risks caused by the artificial water-control schemes have derived remarkably from underestimations of the complexity and integrated nature of the local inhabitant's livelihoods.

The study found that livelihood strategies of local inhabitants are diverse and dynamic even they live in the same circumstance. The resource capitals owned by each social group are driven factors to influence the livelihood paths chosen by households and individuals, and the livelihood strategies are deployed to mitigate negative externalities from the high dyke construction. The diversification of local livelihoods does not necessarily result in improvement, yet it may lead to worsen conditions.

The ways of life of local inhabitants have been changing in response to the socio-economic conditions generated by the high dyke construction. Local livelihoods are built on prioritizing between income and expenditure. Diversification of the household economy from on-farming to non-farming and other activities has been limited to the poor and landless people. Income-generating opportunities are much dependent on accessing to productive assets, which is defined by the wealth differentiation among social groups. The greater one's wealth, the better opportunities one has to earn income from diverse capital sources. The better-off farmers are able to take advantage of changes in the economy, with only minor losses. They seem not as vulnerable to shocks as the poor.
This study shows the need for recognizing the Mekong Delta as a geographical place where the interplay between human, environment and livelihood opportunities differs between social groups. Therefore, national policies on agricultural development should be formulated and implemented to take into consideration the anticipated social impacts on different social groups in the society.

The popular assumption of development planners believe that people will have the same benefit from a particular positive motivation being proven false. Rather, diversity and dynamism of livelihoods are certainly obstacles to the poor, so critical attention has to be given to the most affected social groups if development projects such as the high dyke construction have as its primary goal in improving the lives of people.

\section{Acknowledgements}

The author gratefully acknowledges all participants for their willingness to provide information for this research. The study undertaken by the author was partially funded by the Research Center for Rural Development, An Giang University-Vietnam National University Ho Chi Minh City.

\section{References}

[1] Van de Walle, D. and Cratty, D. (2004). "Is the emerging nonfarm market economy the route out of poverty in Vietnam". Economics of Transition, Vol. 12 (2) 2004, 237-274.

[2] Le Coq, J. F. and Trebuil, G. (2001). "History of Rice Production in the Mekong Delta", paper presented at the third Euroseas Conference. London, UK.

[3] Thanh, D. V (2009). Dike Construction, Social Differentiation, and Local Adaptive Strategies: A Case Study of a Farming Village in the Mekong Delta, Vietnam. MA Thesis. Chiang Mai University.

[4] Sanh, N. V., Xuan, V. T. and Phong, T. A. (1998). "History and Future of Farming Systems in the Mekong Delta" in Xuan, V. T. and Matsui, S. (eds.), Development of Farming Systems in the Mekong Delta (pp. 16-80). Japan International Research Centre for Agricultural Sciences (JIRCAS), Cantho University and Cuu Long Rice Research Institute (CLRRI), Ho Chi Minh City, Vietnam.

[5] Son, D. K. (1998). "History and Future of Farming Systems in the Mekong Delta" in Xuan, V. T. and Matsui, S. (eds.), Development of Farming Systems in the Mekong Delta (pp. 16-80). Japan International Research Centre for Agricultural Sciences (JIRCAS), Cantho University and Cuu Long Rice Research Institute (CLRRI), Ho Chi Minh City, Vietnam.

[6] Husken, F. and White, B. (1989). "Java: Social Differentiation, Food Production, and Agrarian Control", in Hart, Turton and White (eds.) Agrarian Transformations: Local Processes and the State in Southeast Asia (pp. 235-265). Berkeley: University of California Press.

[7] Phrek Gypmantasiri (2002). “Agrarian Transformation and Areal Differentiation in Northern Thailand", in Umehara (eds.) Agrarian Transformation and Areal Differentiation in Globalizing Southeast Asia (pp. 134-159). Tokyo: Rikkyo University Center for Asian Area Studies. 
[8] Akram-Lodhi, H. (2005). "Vietnam Agriculture: Processes of Rich Peasant Accumulation and Mechanism of Social Differentiation", Journal of Agrarian Change 5 (1): 73-116.

[9] Yamazaki, R. (2004). Agriculture in the Mekong Delta of Vietnam. France : Louma Productions.

[10] Hashimoto, T. R. (2001). Environmental Issues and Recent Infrastructure Development in the Mekong Delta: Review, analysis and recommendations with particular reference to large-scale water control projects and the development of coastal areas. Working Paper Series No. 4. Australian Mekong Resource Centre University of Sydney, Australia.

[11] Howie, C. (2005). "High Dykes in the Mekong Delta in Vietnam Bring Social Gains and Environmental Pains." Aquaculture News 32: 15-17.

[12] Nha, D. V. (2006). "Đánh giá tác động của đê bao đến điều kiện kinh tế-xã hội và môi trường trên địa bàn tỉnh An Giang (Dyke Impacts' Assessment to Socio-Economic and Environmental Conditions in An Giang Province). Vietnamese and the Netherlands Research Program, Ministry of ScienceTechnology- Environment, Hanoi, Vietnam.

[13] Thanh Duy Vo (2012). "The impacts of abnormal flood on rice farmers in Vinh Phuoc commnune, Tri Ton district, An Giang province." A scientific report funded by An Giang University.

[14] Kien, N. V. (2006). The Cost and Benefit of Dyke Systems in the Mekong Delta. M. A. Thesis, Australian National University.

[15] Creswell, J., and V. Clark (2011). Designing and conducting mixed methods research. California: Sage Publications.

[16] Nguyen Huu Nhan, Le Viet Hoa, Shigeco Haruyama and Tran Thanh Cong (2007). The Historical Flood in 2000 in Mekong River Delta, Vietnam: A Quantitative Analysis and Simulation. Chirigaku Hyoron/Geographical Review of Japan 80 (12): 663-680. DOI: 10.4157/grj.80.663.

[17] Tinh, D. Q and Hang, P. T. (2003). Living with Floods in the Mekong River Delta of Vietnam. Paper for 3 World Water Forum, Poverty and Flood Theme.

[18] IUCN Vietnam (2010). Mekong Delta situation analysis. A roundtable discussion among Mekong Detla experts, published on IUCN Vietnam website.

[19] Tuan Anh Le, T. H. Chu, F. Miller, and T. S. Bach (2007). Flood and salinity management in the Mekong Delta, Vietnam. Literature Analysis Challenges to Sustainable Development in the Mekong Delta: Regional and National Policy Issues and Research Needs.

[20] Ninh, N. H. (2007). Flooding in Mekong River Delta, Viet Nam. Human Development Report 2007/2008. Fighting climate change: Human solidarity in a divided world Human Development Report Office OCCASIONAL PAPER.

[21] Tin, N. T. and Ghassemi, F. (1999). Availability and Quality of
Surface Water Resources. Report for the ACIAR Project: An evaluation of the sustainability of farming systems in the brackish water region of the Mekong Delta. Centre for Water Quality and Environment and Centre for Resource and Environmental Studies, Ho Chi Minh City, Vietnam.

[22] Evers, Hans-Dieter and Benedikter, Simon (2009). Strategic Group Formation in the Mekong Delta - The Development of a Modern Hydraulic Society. MPRA Paper. No. 13796. Munich Personal RePEc Archive.

[23] Osborne, Milton (2004). river at risk: The Mekong and the Water Politics of China and Southeast Asia. Lowy Institute for International Policy.

[24] Label, L. and Bach Tan Sinh (2007). "Politics of Floods and disasters", in Label et al. (eds.) Democratizing Water Governance in the Mekong Region. USER MEKONG PRESS.

[25] Thong Anh Tran and Helen James (2017). Transformation of household livelihoods in adapting to the impacts of flood control schemes in the Vietnamese Mekong Delta. Water Resources and Rural Development 9. DOI: 10.1016/j.wrr.2017.04.002.

[26] Kakonen, Mira (2008). Mekong Delta at the Crossroad: More Control or Adaptation? In: Ambio Vol. 73, No. 3, May 2008. Pp. 205-212.

[27] GSO (General Statistics Office) (2014). Statistical Yearbook. Statistical Publishing House, Hanoi, Vietnam.

[28] Nguyen Huu Tri, Vo Duy Thanh and Tran Anh Thong (2012). Vitality of Sediments and Wild Fish to Households in the Mekong Delta of Vietnam and the Implications of Hydropower Dam Project on the Mekong Mainstream: A Case Study in An Giang Province. A scientific report to Vietnam Rivers Network (VRN).

[29] Ellis, F. (2000). Rural Livelihood and Diversity in Developing Countries. Oxford: University of Oxford Press.

[30] Yos Santasombat (2008). Flexible Peasant: Reconceptualizing the Third World's Rural Types. Chiang Mai: RCSD, Faculty of Social Sciences, Chiang Mai University.

\section{Biography}

Thanh Duy Vo is a lecturer and researcher at the Research Center for Rural Development, An Giang University-Vietnam National University Ho Chi Minh City, Vietnam. Thanh obtained his Ph. D. degree in cultural anthropology (2020) at the Australian National University. Thanh previously earned his M. A. degree in Sustainable Development (2009) at the Regional Center for Sustainable Development of Chiang Mai University, Thailand. He has published several academic journals in cultural anthropology and sustainable development in the Vietnamese Mekong Delta. 